\title{
Event-related-potential (ERP) markers of traumatic brain injury (TBI) severity and cognitive function - Understanding how the brain works and thinks post TBI
}

\author{
Miranda P1, Christopher D Cox ${ }^{2}$, Alexander Mํ, Danev $S^{3}$ and Jonathan RT Lakey ${ }^{\text {* }}$ \\ ${ }^{1}$ Department of Surgery and Biomedical Engineering, University of California Irvine, California, USA \\ ${ }^{2}$ Department of Neurology, David Geffen School of Medicine, University of California, LosAngeles, California, USA \\ ${ }^{3}$ Medeia Inc, Santa Barbara, CA, USA
}

\begin{abstract}
One fact is that other injuries often co-occur with traumatic brain Injury (TBI), thus event related potentials (ERPs) elicited using electroencephalography (EEG) machines like NeuralScan by Medeia often reflect the sum of both injuries. The second fact is that cognitive function includes domains from knowledge, attention, memory and working memory, judgment and evaluation, reasoning and "computation" to problem solving and decision-making. The third is that cross-border mental or neurocognitive or non-traumatic brain disorders that exhibit similar symptoms post-TBI will exhibit impairments in similar domains. Therefore, what if observing similar a) altered EEG-functional connectivity in post-TBI as in Alzheimer's, epileptic seizures, schizophrenia, stroke etc or b) altered network geometries in postTBI as in CNS tumors, depression etc is the status quo? What if the reason we are not able to identify pathognomic ERP-markers of cognitive impairment post-TBI that are highly specific and sensitive is simply because we are not thinking as the brain does? What if trying to validate ERP markers of TBI-severity and cognitive function post-TBI in the same manner one validates a candidate diagnostic test is what's wrong in the first place? Is it possible that domain- and symptom-based identification, management and treatment of cognitive-impairments or TBI-severity are the way to go?
\end{abstract}

\section{Introduction}

Three key features influencing traumatic brain injury (TBI), management and rehabilitation outcomes are; a) psychiatric post-TBI sequelae, b) neurological and neuropsychiatric post-TBI sequelae and c) other injuries co-existing with TBI. The prevalence of some of the psychiatric post-TBI sequelae include; depression: $18.5 \%-61 \%$, mania: $4.20 \%$, obsessive-compulsive disorder (OCD): $1.6 \%-15 \%$, posttraumatic stress disorder (PTSD): $3 \%-27.1 \%$, psychosis: $0.7 \%$, alcohol-related disorders: $34.9 \%-51 \%$, and that of personality changes like, apathy: $34.5 \%$, affective lability: 5\%-32.7\%, aggression: $16.4 \%-33.7 \%$ [1-11].

Computerized tomography (CT) imaging of individuals with depression following TBI exhibited decreased bilateral hippocampal and left prefrontal grey matter volume and lesions in the left frontal, dorsolateral and basal ganglia [12-15]. Subjects with mania post-TBI had seizures and showed temporal basal pole lesions [16-18]. Individuals with OCD following TBI showed damage in the oribitofrontal and cingulate cortex and caudate nucleus [19-21]. Similarly in cases of PTSD post-TBI cerebrospinal fluid (CSF) of S-100B levels increased [22]. Psychosis post-TBI with frontal and temporal lobe damage had electroencephalography (EEG) abnormalities; seizures and cognitive impairment was global [23-27]. Individuals with alcohol-related disorders post-TBI showed generalized brain atrophy, reduction in prefrontal cortical (PFC) volume and EEG studies revealed changes in their event-related potential (ERP) patterns; however these patterns returned to no-alcohol-consumption post-TBI patterns if individuals observed abstinence from alcohol (28-30). Personality changes like apathy seen in individuals post-TBI was characterized by subcortical damage while those with, affective lability and aggression exhibited frontal lobe damage [11,28-33].
Neurological and neuropsychiatric post-TBI sequelae seen include neurodegenerative diseases (Alzheimer's disease (AD), Parkinson's disease (PD), and amyotrophic lateral sclerosis (ALS)), attentiondeficit/hyperactivity disorder (ADHD), autism spectrum disorder (ASD) and schizophrenia [34-45]. The homology between TBI and its psychiatric, neurological and neuropsychiatric post-TBI sequelae has been found to extend from its symptoms, to cortical regions involved, to functional connectivity and synchronization of EEGs to exist between genomic signatures (in a landmark study in 2017) from blood and brain (Figure 1a) [46]. The study used a rodent TBI model to illustrate how TBI imposed a predisposition to the post-TBI psychiatric, neurological and neuropsychiatric sequelae seen. The finding was that TBI affected gene regulatory mechanisms (key driver (KD) genes) involved in cerebral homeostasis influencing epigenomic programming, splicing and transcription factors, and novel network regulators. Simply put, TBI affected $\mathrm{KD}$ genes adversely resulting in an increased predisposition to developing ADHD, ASD, PD, AD, PTSD, epilepsy/seizures, stroke, depression and schizophrenia post-TBI.

Another confounding factor in most TBI studies is that while most TBI studies compare healthy controls versus those with TBI, none clearly stipulate that individuals with only TBI and no other general injury were studied [47]. However, it is natural that cortical EEG, qEEG patterns would reflect the sum of both TBI and general injuries an

${ }^{\star}$ Correspondence to: Jonathan RT Lakey, PhD, MSM, Department of Surgery, 333 City Blvd West, Suite 1600, Orange, CA 92868, USA, E-mail: jlakey@uci.edu Received: March 11, 2020; Accepted: April 06, 2020; Published: April 10, 2020 
Miranda P (2020) Event-related-potential (ERP) markers of traumatic brain injury (TBI) severity and cognitive function - Understanding how the brain works and thinks post TBI

individual has sustained or is recovering from as illustrated in (Figure $1 b)$.

Post-TBI symptoms experienced by individuals with TBI range from mild to severe range from nausea, confusion, dizziness, blurred vision, headaches, agitation, to mood changes while neurocognitive impairments range from memory, attention, executive functioning, to processing speed [48-53]. These symptoms can persist from a few days, weeks, months, and years to a lifetime $[48,49]$. There are tests to assess post-TBI symptoms due to moderate and severe TBI [54-59]. Mild TBI still poses a problem as its symptoms manifest later in certain instances or are transient, nevertheless the symptoms can affect the quality of life, education, employment, performance, the social and relationship domain and in some cases even endanger life $[48,49]$.

However as early as 1993 it was clearly established that post-trauma consequences of mTBI were not always mild and that electrophysiology (EEG) could contribute significantly to a better understanding, management and treatment of the same [50]. In instances where impairments require more sensitive and fine-grained tests using EEG and event-related potentials (ERPs) could provide an endogenous viewpoint of cognitive processes and changes in cortical function, aspects that imaging cannot capture. In this context the present paper examines if domain- and symptom-based EEG and ERP markers of cognitive-impairments or TBI-severity using EEG machines like NeuralScan by Medeia would be a more appropriate approach.

\section{Auditory evoked potentials (AEPs)}

The cognitive domains memory, attention, and processing speed are most commonly affected following TBI [51-53]. Alterations/ impairments in these domains can be accessed via the neural correlates of the auditory system to which they are innately intertwined via AEPs [54-61]. Figure 2a presents the AEP components (adapted from Gaetz \& Bernstein, 2001) that include early AEPs (auditory brainstem response (ABR), complex $\mathrm{ABR}$ (cABR)), auditory middle latency response (AMLR), and auditory late latency response (ALLR) [51,62]. Figure 3 presents an illustrated example of how AEPs can be recorded using EEG machines like NeuralScan.

Among click-evoked ABR studies; latencies and amplitude of waveforms-I, -III, and $-\mathrm{V}$ were similar for mTBI $(n=19)$ and no TBI $(\mathrm{n}=29)$ in a study by Gallun et al., concussed $(\mathrm{n}=11)$ showed a delayed wave-III latency versus control $(n=12)$ participants and reduced interpeak latency difference was seen in mTBI $(n=15)$ versus 35 controls [63-65]. FFR a component of the complex ABR was reduced and slower responses to fundamental frequency $\left(\mathrm{F}_{0}\right)$ and poor pitch coding was seen in concussion $(n=20)$ versus control $(n=20)$ participants in a study by Kraus et al. [66].

In terms of click-evoked ABR and AMLR studies: Munjal, Panda, and Pathak studied 50 controls versus $\mathrm{mTBI}=100$, moderate TBI $=150$, severe $\mathrm{TBI}=40$ ) [67]. With severity of TBI wave-latency and I-V interpeak latency of ABR increased while AMLR's showed decreased amplitude of $\mathrm{Na}$ and $\mathrm{Pa}$ components [66]. Soustiel et al. found prolonged $\mathrm{Na}$ and $\mathrm{Pa}$ waveforms in 15 of the 40 mTBI participants versus 23 controls, while Drake et al. found prolonged latency of $\mathrm{Pa}$ and reduced amplitude of $\mathrm{Pa}$ and $\mathrm{Na}$ waveforms in 20 participants with mTBI versus 20 controls [68,69]. A pulse-evoked AMLR study by Arciniegas et al. on $\mathrm{mTBI}=5$, moderate $\mathrm{TBI}=6$, severe $\mathrm{TBI}=9$ versus 20 control showed significant differences in P50 amplitude and P50 ratio between mTBI and controls [70]. 1a: Overlapping genes between TBI hippocampal signatures or KDs and human GWAS genes of brain disorders

\begin{tabular}{|c|c|}
\hline GWAS disease & Overlapping gene in TBI hippocampal signature \\
\hline $\begin{array}{l}\text { Alcohol } \\
\text { consumption/dependence }\end{array}$ & CUX2; SLC26A4: ZDHHC21; ESR1; SERINC2 \\
\hline & 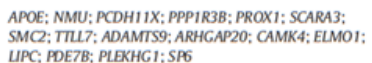 \\
\hline ADHD & 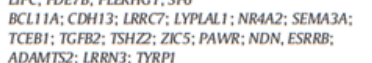 \\
\hline Bipolar disorder & 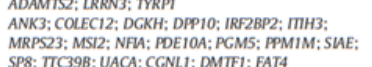 \\
\hline $\begin{array}{l}\text { Bipolar disorder and } \\
\text { schizophrenia }\end{array}$ & 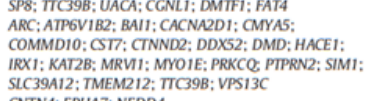 \\
\hline $\begin{array}{l}\text { Brain connectivity } \\
\text { Brain structure }\end{array}$ & CNTN4: EPHA7; NEDD4 \\
\hline $\begin{array}{l}\text { Brain structure } \\
\text { Cognitive function }\end{array}$ & 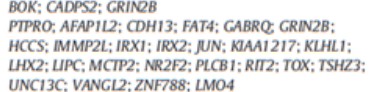 \\
\hline Word reading & NOSIAP, TACSID2; TYRPI \\
\hline $\begin{array}{l}\text { Working memory } \\
\text { Conduct disorder }\end{array}$ & $\begin{array}{l}\text { CDNI: DRD2: LPHN3 } \\
\text { CIQTNF7; MCTP2; NR2F2; RIT2; STSSIA4; ZBTB16; } \\
\text { KCNAS; PDEIOA }\end{array}$ \\
\hline Eating disorders & CAMKID: DLGAP1 \\
\hline $\begin{array}{l}\text { Hippocampal } \\
\text { atrophy/volume }\end{array}$ & APOE; COL18AI: F5: MAGI2; MAL2; DPP4; MSRB3 \\
\hline Intelligence & CNTN4; COLIA2; CYPC; KIF16B \\
\hline Major depressive disorder & $\begin{array}{l}\text { ADCYAPIRI; CCND2; CDH9; EMPI; GRINQB; HAPLNI: } \\
\text { HOMERI: IGFBP3; KCNH5; NDFIP2; NEUROD6; PCLO; } \\
\text { RASGEFIB; ATPGVIB2 }\end{array}$ \\
\hline Parkinson's disease & $\begin{array}{l}\text { BMP4; DLG2; GPRIN3; RTI2; RORA; SEMASA: STK39; } \\
\text { VPSI3C; WNT3 }\end{array}$ \\
\hline PTSD & COBL: PCSK2: PRKCA: SLCAAS \\
\hline Schizophrenia & $\begin{array}{l}\text { ANK3; BMP7; CDH13; СC12; GNAL; NRGN: } \\
\text { PCDH2O; PDC; PTCS2; RORA; SNX7; TCF4: VPS13C }\end{array}$ \\
\hline Smoking behavior & BDNF; CHRNA3; CHRNAS; KCND2; MAOB; PDEIC \\
\hline
\end{tabular}

1b: Spectral maps showing P300 response to the oddball target tone

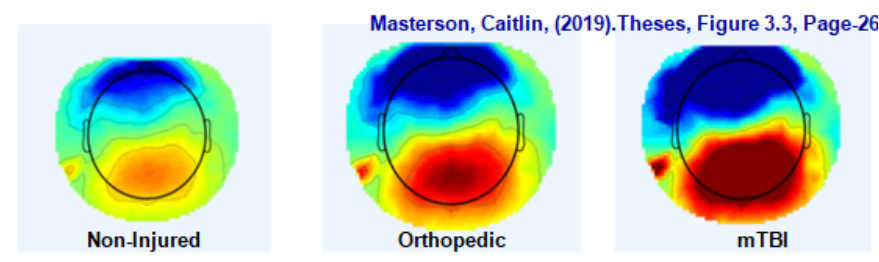

Figure 1. Factoring in Homology and the other-injury factor when looking for markers of TBI- and neurocognition $[46,47]$

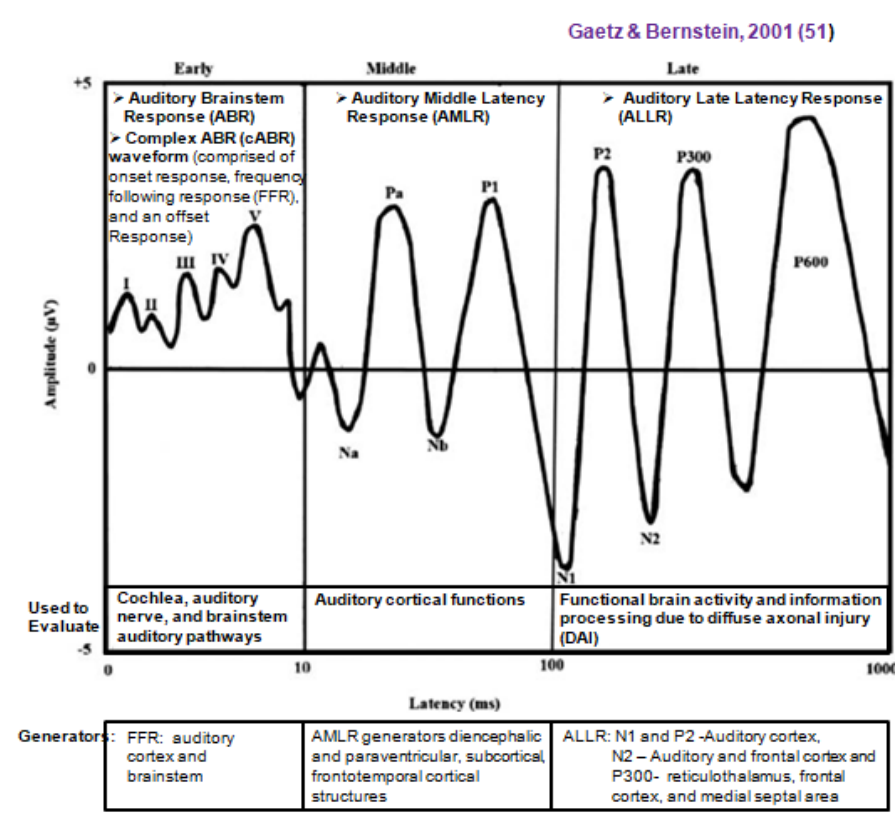

Figure 2. Auditory evoked potentials (AEPs) 
Miranda P (2020) Event-related-potential (ERP) markers of traumatic brain injury (TBI) severity and cognitive function - Understanding how the brain works and thinks post TBI

\section{NeuralScan}

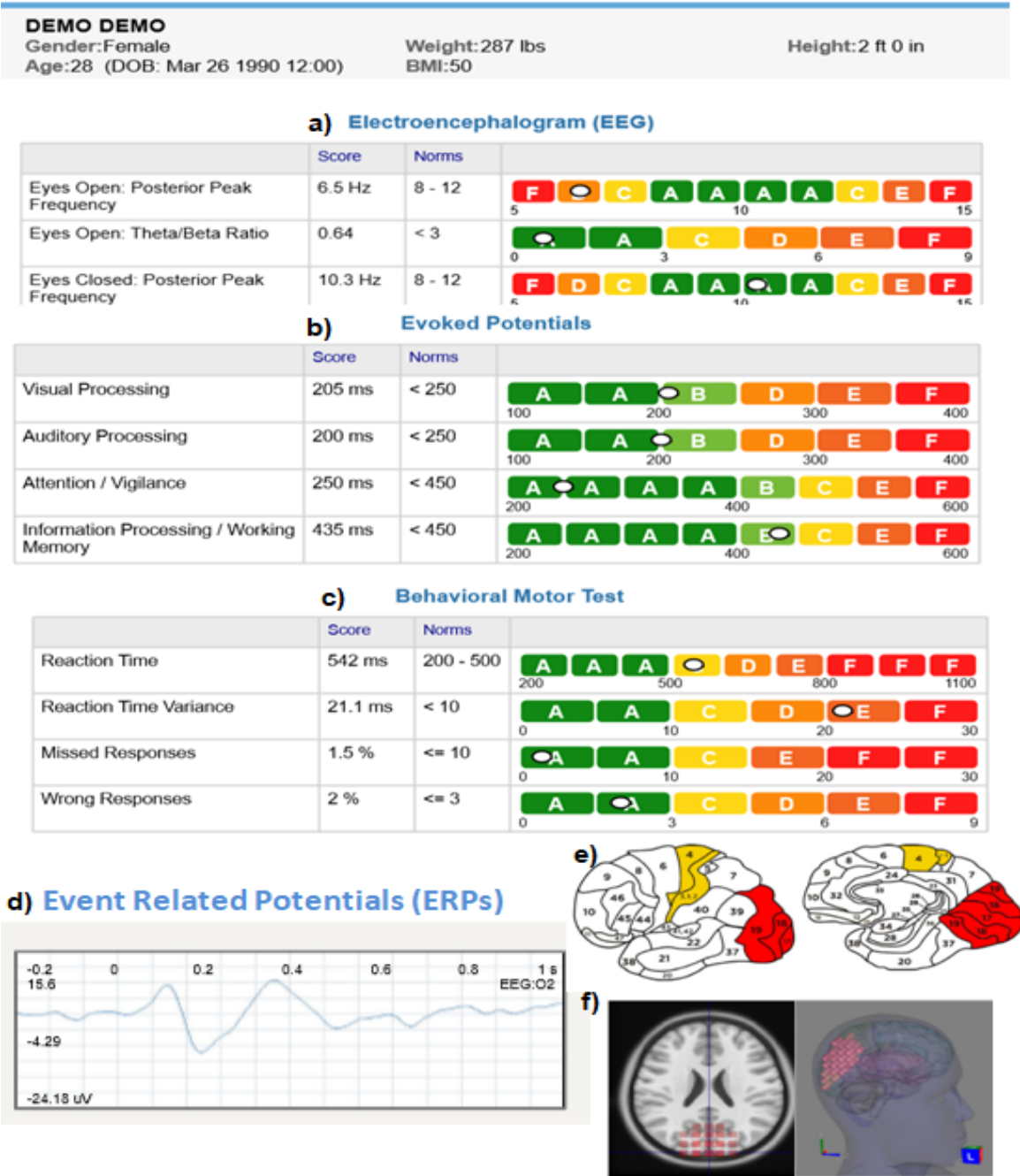

Figure 3. Illustration of AEPs, VEPs, and cognitive function captured using NeuralScan by Medeia.

a)19-channel EEG (not shown) Resting EEG capturing ability (eyes open, eyes closed condition), missed and wrong responses, b) Evoked potentials: VEP, AEP, Attention, Working Memory. c) Reaction-time (RT), RT variance (RTV), Fi d) Event related potentials (ERPs), e) identification of Broadmann areas affected and f) source location using LORETA

AERPs evoked using auditory oddball tasks showed overall prolonged P3 latencies and reduced amplitude of N1, P2, and P3 waveforms in concussed $(\mathrm{n}=40)$ groups study by Gosselin et al. [71]. However, smaller P2 amplitudes were seen in 20 symptomatic versus 20 asymptomatic collegiate athletes versus 20 control participants. Solbakk et al. observed reduced N2 and P3 amplitudes in mTBI $(n=15)$ participants versus 13 controls [72]. Decrease P3b amplitude with increased latency was observed by Pratap-Chand et al. in 20 participants with mTBI versus 20 matched controls [73]. Segalowitz et al. used four auditory oddball tasks to elicit AERPs [74]. Reduced amplitudes of P3a and P3b were observed in 10 participants with mTBI versus 12 controls. High school athletes $(\mathrm{n}=30)$ were studied by Thériault et al. [75]. Smaller P3a and P3b amplitudes were observed in both recently concussed $(n=10)$ and late concussion $(n=10)$ athletes versus controls $(\mathrm{n}=10)$. Further late concussed had larger P3b amplitude versus recent concussed i.e. though they appeared to function normally endogenously their neuronal function had altered at the sub-clinical level.

Another study where AEPs evoked using standard and target stimuli were recorded in 19 healthy, 17 with mTBI at 7 days post-TBI and 17 mTBI both at 7 days and 2-3 months post-TBI also showed prolonged P300 latency at 7 days which appeared to improve at 2-3 months [76], In terms of cognitive domains these studies found that memory processing and frontal lobe efficiency were affected by decline in attention resources as a result when novel stimuli were presented the response/reaction time was altered which resulted in the chronic motor and cognitive changes seen post-TBI. Similar findings were seen in another study of 24 individuals with mTBI versus 24 healthy controls P3a was more negative following a three-stimulus AEP task [77]. P3a and P3b decrease in amplitude and latency was also seen in another on 40 healthy former athletes in late adulthood, 19 of which had had mTBI in early adulthood while 21 had no history of TBI [78]. Preventing a general consensus is that while several studies have demonstrated delay in latencies for waves-I, -III and -V in mTBI versus controls there are others have reported no difference between controls and individuals with blunt head trauma/soccer players/boxers/athletes [68,79-90].

\section{Visual evoked potential (VEP)}

Following mTBI individuals often vision related issues like oculomotor and accommodative dysfunctions, binocular vision 

thinks post TBI

deficits, compromised visual field sensitivity, deficits in binocular vision, visual memory, visual attention, perception and visual information processing [91,92]. Vestibular spatial localization errors, and visuomotor coordination impairment are also common $[7,8]$. More importantly oculomotor deficits are not self-resolving as other TBI injuries and often require oculomotor-based vision therapy [93-95]. $90 \%$ of individuals following mTBI suffer from oculomotor dysfunction. oculomotor dysfunction, 10-40\% accommodative deficiencies and 50\% light sensitivity that affect fine binocular oculomotor coordination as one scans across a line of text, textual clarity and limits reading duration and comfort and one's maximum respectively [96-101].

In a multimodality-evoked-potential (MEP) prospective study of 18 mTBI subjects VEP was carried out at 2-weeks post injury (Figure 3 presents results of VEPs recorded using EEG machines like NeuralScan). P100 showed no difference beyond 3SD (standard deviations) [102]. Pattern reversal visual evoked potentials (PR-VEPs) recorded in 20 controls and $50 \mathrm{mTBI}$ subjects on days- 1 and -30 post-trauma While subjects had no visual complaints and P100 amplitude and latency showed no significant differences between groups, the latency declined and amplitude increased significantly when mTBI on day-30 was compared with day-1. These findings highlight the usefulness of the P100 in detecting sub-clinical visual changes post-TBI [103]. On a study of the organic basis of persistent post-concussion syndrome, latency was beyond $2.5 \mathrm{SD}$ in $30 \%$ of mTBI and P100 amplitudes declined significantly when compared to controls [104]. In a study evaluating the long-terms effects of sport-related concussion 18 with history of concussion and 18 controls were evaluated using patternreversal VEP tasks. Subjects $\approx 6.7$ years post-BI, exhibited reduced P1 amplitude independent of duration post injury and the number of injuries. Further sensory-mediated response inhibition (Erickson flanker task) tasks showed that P1 amplitude and P3 amplitude and latency (attention) were significantly related in healthy controls but not in mTBI. For post-TBI subjects P1 amplitude was inversely related to the number of errors of commission but this was not observed in controls. Decline in efficiency of sensory capture could have caused this deficit in attentional resource allocation and inhibition seen [105].

Studies aimed at determining markers capable of differentiating between mTBI and no-TBI or markers to help track recovery were also carried out. Pattern VEP testing was carried out in a study that looked at the response of individuals with mTBI (1-10 years post-injury, $\mathrm{n}=19)$ versus visually-normal $(\mathrm{VN}, \mathrm{n}=20)$ and the degree of luminance (baseline luminance versus luminance reduced using neutral densityND filters:0.5, 1.0, 1.5, 2.0 and 2.5). Overall, in both groups mean VEP amplitude declined $(\mathrm{p}<0.05)$ and latency increased $(\mathrm{p}<0.05)$ with the degree of luminance. At each luminance level the mTBI group showed significant amplitude reduction $(\mathrm{p}<0.05)$ and latency increase $(\mathrm{p}<0.05)$ when compared with the VN group. These findings suggest that individuals with mTBI can be differentiated from VN using VEP and the degree of luminance and should ophthalmological rehabilitation be considered the same can be used to track recovery [106]. Another study evaluated visual attention changes using VEP in individuals with mTBI alone $(n=5)$ and in those with self-reported attention deficit hyperactivity disorder (ADHD, $n=11$ ) following mTBI. Visual attention changes using VEP alpha band attenuation ratio (AR, both individual and combined alpha frequencies) was evaluated using a) pattern VEP; b) eyes-closed; and c) eyes-closed with number counting. While AR was normal in individuals with mTBI alone it was abnormal in those with mTBI+ADHD. This let Yadav et al. to conclude that AR could be used to identify individuals with ADHD post-mTBI [107].
12 adults with mTBI and $12 \mathrm{VN}$ individuals were provided with 'precision tint lenses', and intuitive colorimeter system, visagraph and VEP amplitude and latency were recorded [23]. Few significant differences were seen in reading and VEP parameters suggesting that tinted lenses might be a first line measure to relieve initial discomfort prior to long-term strategies like vision therapy [108]. A texture segregation VEPs (tsVEP) study on 13 individuals with mTBI and 13 controls found that tsVEP peaks increased in individuals with mTBI compared with controls while low-level VEPs (llVEP) remained within normal patterns. The inference was that tsVEP elicited after llVEP (around $100 \mathrm{~ms}$ ) and prior to $300 \mathrm{~ms}$ could be used to detect damage to complex visual pathways that are neuroradiologically silent [109].

In a study evaluating convergence insufficiency in normal patients versus post-mTBI subjects were exposed to sustained stimuli (2-rev/s, $85 \%$ contrast checkerboard patterns of 1- and 2-degree check sizes) and transient stimuli (4-rev/s, $10 \%$ contrast vertical sinusoidal gratings with column width of 0.25 and 0.50 cycles/degree) [110]. Two models were compared (one from a priori clinical study and one derived using study data) for their discriminatory ability between individuals with convergence insufficiency with and without mTBI and had an accuracy of $76 \%$ and $86 \%$ respectively. The resultant receiver operating characteristic curve for the new model had a sensitivity of 0.92 , specificity 0.80 and area under the curve $(\mathrm{AUC})=0.857 ; p<0.01$ [110]. In a case study on neurophysiological and cognitive functions post sport-related mTBI (8-year old, female, soccer injury) VEPs recorded at 7 weeks preinjury and $24 \mathrm{~h}, 7,22,32$ and 55 weeks post-injury were analyzed [111]. At $24 \mathrm{~h}$ post-TBI attention-related cognitive impairments manifested some of which resolved within 22 weeks. VEPs and spectral analyses 1 -year post-mTBI indicated cognitive impairments in the vigilance and attention, domain that also impacted on school performance.

Broglio et al. studied 44 individuals without TBI and 46 with previous mTBI using ImPACT and ERPs using three-stimulus oddball task. While groups did not differ in their ImPACT scores N2 and P3b amplitudes declined significantly in those with a history of TBI. They concluded that persistent impairments in the domains of attention suggest that one could no longer characterize mTBI a transient with short-term cognitive impairments instead one could not predict which neuropathologies would clinically persist or manifest at a later time point [112].

In two successive studies Gosselin et al. examined the root cause of persistant symptoms post-TBI [113,114]. Using functional magnetic resonance imaging (fMRI), blood-oxygen-level-dependent (BOLD) signal changes and ERPs they compared 14 mTBI subjects with 23 controls [113]. fMRI findings were positively correlated while BOLD signal changes and N350 amplitude were inversely correlated with symptom severity. In a subsequent study Gosselin et al. study working memory $(\mathrm{WM})$ performance following mTBI $(\mathrm{n}=44)$ and 40 controls. Amplitude and latency of frontal (N200 and N350) and parietal (P200 and P300) were studied. Groups did not differ by ERP latency [114]; however, mTBI had significantly smaller N350 and P300 amplitudes, slower reaction times, worse accuracy and a lower percentage of correct answers than the control group $(\mathrm{p}<0.05)$. They reported that given current follow-up testing for mTBI clinicians may fail to detect and therefore treat consequences of mTBI especially if sub-clinical cerebral/ cortical dysfunction existed.

Lachapelle showed that selective deficits in complex visual information processing in individuals with symptomatic mTBI could interfere with vocational outcome [115]. Pattern-reversal, simple 

thinks post TBI

motion, texture segregation and cognitive oddball paradigms were studied in 17 individuals with symptomatic mTBI and 15 controls. mTBI had significantly lower amplitudes, and prolonged latencies for cognitive paradigms and tsVEP $(\mathrm{p}<0.05)$. In contrast Di Russo studied ERP (elicited using Go/No-Go task) changes following injuries due to professional boxing and fencing versus non-athletes [116]. While attention and motor response control improved in fencing, cumulative injuries to the head due to boxing resulted in prolonged and decreased P300. Another study on 20 college contact sport athletes also had similar results with marked decline in P300 amplitude attributed to the attention-cognitive domain [117].

The N-back working memory test was performed on 3 different visits on 11 mTBI patients and 7 controls, on three different visits. P300 amplitude and latency revealed that latencies were significantly shorter in controls at every visit while the mTBI group did not show any such improvement. The finding reiterated the persistent nature of mTBI symptoms [118]. Potter et al. demonstrated that to achieve an equivalent performance as controls the mTBI group allocated greater attention resources. The mTBI were as fast as controls for the computer-based Stroop tasks but they made more errors. The mTBI group for the card-based Stroop congruent and incongruent tasks were slower and made even more errors and had greater negativity in latency (350 to 450 $\mathrm{ms}$ ) for the incongruent tasks (greater allocation of attention resources) than to the congruent tasks [119].

Conflict monitoring and adaptation (N450 and conflict SP ERP components) were studied Larson et al. in 29 mild TBI and 36 control using Stroop tasks (50\% congruent and 50\% incongruent trials). Findings were that normal conflict SP sensitive to conflict adaptation in healthy individuals declined in individuals with mTBI resulting in mTBI individuals exhibiting intact conflict monitoring, but altered conflict adaptation and adjustment processes [120]. Larson et al. also found comparable performance of mTBI $(n=36)$ to controls $(n=46)$ in certain aspects of cognitive control. The group measured error-related negativity (ERN), post-error positivity (Pe) components, behavioral (response times $[\mathrm{RT}]$ and error rates) following a modified colornaming Stroop task [121].

\section{ERPs pertinent to cognitive and social function following TBI}

Cognitive function encompasses processes, including knowledge, attention, memory and working memory, judgment and evaluation, reasoning and "computation", problem solving and decision-making, comprehension and production of language. Social function includes; personality, thinking, behavior and perception of social cues. Both cognitive and social function can be impaired following TBI [120,122131]. Among them reduction in processing speed, memory, inability to sustain attention and engage socially are common cognitive impairments seen $[12,13,132]$. Affecting both personal and social performance is other cognitive failures TBI subjects often report facing in their everyday life. These range from repetitive mistakes to inhibition control and lack of awareness both of which can result in impulsive and socially inappropriate behavior [133-136]. Following TBI impairment in word retrieval is often seen particularly among athletes which effects both every day and official communication [137-140].

For instance among studies on ERPs, cognitive function and outcomes following TBI, Shah et al. found elevated frontal midline theta power and reduction of frontal beta power a pattern that correlated with executive attention impairment $(r=-0.67, p<0.001)$ in TBI subjects [141-143]. These patterns are attributed to the destruction of afferent nerve connections and inhibition due to hyperpolarized neurons a condition caused by temporal absence of excitatory synaptic activity (disfacilitation) of the medial frontal neuronal population [141]. Another study looked at working memory (WM) using continuous performance task (N-back) at 5-days, 2-weeks, and 1-month post-mTBI (143). Arakaki et al. found subjects with mTBI patients had increased frontal event-related desynchronization (ERD) at 5-days and 1-month, (Visit-1 and Visit-3) for induced alpha power. For evoked alpha, mTBI patients had lower parietal ERD/event-related synchronization (ERS) at the second and third visits [143]. In the area of cognitive rehabilitation, Porter et al. carried out a 3-month cognitive intervention program $[144,145]$. TBI subjects showed significant improvements in their composite cognitive score and the right inferior frontal gyrus showed significant decline in functional connectivity.

Table 1 presents a rapid yet brief review of ERPs pertinent to cognitive and social function following TBI [146-201]. Figure 3 captures how ERPs pertinent to attention, working memory can be recorded using EEG machines like NeuralScan.

\section{Conclusion - the "third" fact}

Cross-border mental/neurocognitive/non-traumatic brain disorders that exhibit similar symptoms post-TBI will exhibit altered EEG patterns in similar domains. AD, PD, ALS, ADHD ASD and schizophrenia are examples of some of the post-TBI sequelae seen [34-44]. Many of these disorders not only share symptoms but a review carried out in 2015 by Rapp et al. on EEG and quantitative EEG (qEEG) and event-related potential (ERPs) studies to detect TBI showed similar altered functional connectivity, network geometries and synchronization of EEGs [45]. The findings led to the inference that while distinguishing between TBI and healthy controls was possible it would be difficult to distinguish between psychiatric, neurological and neuropsychiatric disorders that either shared symptoms with TBI or were the post-TBI sequelae observed (Table 2) $[45,158,190,202-233]$. A genetic study illustrated that these alterations in functional connectivity and synchronization of EEGs key drivers occurred due TBI's affect on key driver (KD) genes and in turn gene regulatory mechanisms involved in maintaining brain homeostasis from transcription factors to novel network regulators (Figure-1a) [46]. It induced DNA methylomic changes in the hippocampus and leucocytes.

\section{Considering the}

a) inherent overlap and homology between TBI and its psychiatric, neurological and neuropsychiatric post-TBI sequelae,

b) the infinite types of TBI, each injury can activate different pathophysiological processes, recovery can also vary in duration, outcome and post-TBI sequelae can also vary.

c) differences in demographic characteristics of TBI subjects

attempting to validate "specific" ERP markers of TBI-severity and cognitive function post-TBI is perhaps what's wrong in the first place. For reasons mentioned above while differentiating between a healthy control and a TBI subject might be possible differentiating between symptoms post-TBI and neuropsychiatric may be difficult. For the same reasons looking for "specific" EEG/ERP markers may be akin to looking to looking for the "unnatural". However, if one instead looks for domain- and symptom-based markers using EEG machines like NeuralScan one may be able to achieve clinical goals and better characterize, manage and treat each TBI injury and post-TBI sequelae. In layman's terms we could be able to understand how the injured brain, heals, responds to treatment, recovers, works, and thinks post-TBI. 
Miranda P (2020) Event-related-potential (ERP) markers of traumatic brain injury (TBI) severity and cognitive function - Understanding how the brain works and thinks post TBI

Table 1. ERP markers of cognitive and social function in TBI subjects (Adapted and modified from Dockree et al. [195]

\begin{tabular}{|c|c|}
\hline $\operatorname{Cog} n$ & articulars \\
\hline Processing Speed & $\begin{array}{l}\text { Paradigms to assess processing speed } \\
\text { - Using stimulus-locked and response-locked ERPs } \\
\text { - RT delays in TBI patients best seen in fast conditions, with its sensitivity decreasing when RT gets longer. } \\
\text { - Contingent Negative Variation (CNV) waveform: elicited using a warning stimulus (e.g. a tone/ visual cue) followed by a target requiring a response (e.g. } \\
\text { withhold/respond). } \\
\text { Results of studies assessing processing speed } \\
\text { - Meta-analysis of } 13 \mathrm{TBI} \text { studies showed individuals with TBI are } 1.54 \text { times slower than healthy controls [39]. } \\
\text { - Reaction time (RT) is the sum of both input (perceptual) and output (motor execution) processes. Slowed processing speed and RT associated with diffuse } \\
\text { axonal injury (DAI) especially seen in tasks requiring inter-hemispheric transfer of information where white matter integrity is lost/threatened (146]. } \\
\text { - Stimulus locked P300 and a response locked Motor Potential (MP) are reduced in amplitude and delayed in latency in TBI patients compared to controls [147]. } \\
\text { Early perceptual discrimination processes (N1, P2/P250 and N2, amplitude) reduced resulting in delay to the transfer of information from stimulus processing } \\
\text { to response selection (N2 and P300) causing significantly prolonged peak latency in TBI patients compared to controls [148] Longer RTs and longer latency } \\
\text { P3 responses in TBI patients compared to controls [149]. } \\
\text { - Early CNV following cue did not differentiate go and no-go trials. Impaired cue processing might be the cause of longer RT in TBI patients compared to } \\
\text { controls [150-153] } \\
\text { Retraining/treatment for response speed in TBI patients } \\
\text { - Feedback and designated time windows for responding used to shorten the RTs of TBI patients and normalize responding [154]. Patients' RTs speed remained } \\
\text { comparable to controls even after cues were removed [154]. Retrained RTs occurred at the same time as their P300 latencies with no alternation of P300 latency. } \\
\text { Emphasizing speed over accuracy in training may have caused patients to abandon their default strategy of prioritizing accuracy over speed (a compensatory } \\
\text { strategy following TBI) [154]. } \\
\text { - P300 peak latency was also shortened after the administration of cerebrolysin (neurotrophic factor drug that promote synaptic repair in animal models) [154]. }\end{array}$ \\
\hline $\begin{array}{r}\text { Sustai } \\
\text { perf } \\
\text { ph } \\
\text { v }\end{array}$ & 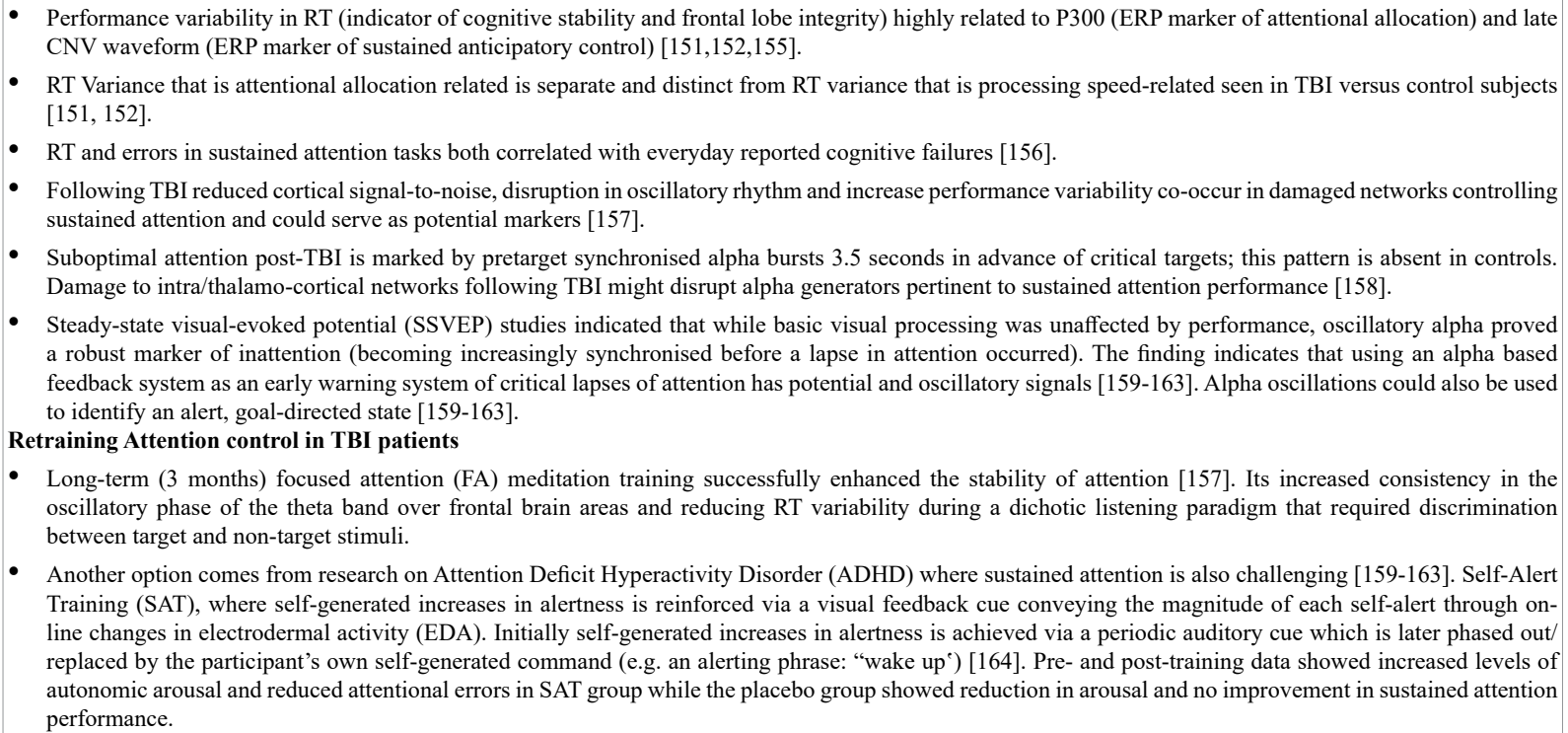 \\
\hline & $\begin{array}{l}\text { - TBI subjects exhibit reduced error awareness on error detection tasks [165,166] } \\
\text { - TBI subjects more likely to accept misleading information as 'remembering' }[167] \\
\text { patients. Error Related Negativity (ERN) and Error Positivity (Pe) neurochemically linked with the mesencephalic dopaminesystem, are critical indicators of } \\
\text { the integrity of error-processing networks [168,169]. } \\
\text { - ERN reflects an early action monitoring system, it detects a) errors prior to conscious processing, b) changing reward contingencies and c) manipulations of } \\
\text { response conflict [170,171]. } \\
\text { - Pe reflects conscious evaluation of error [172,173]. } \\
\text { - ERN produced both when participants are aware/unaware of their error, but error positivity (Pe) is enhanced only when participants are aware of committing } \\
\text { an error. } \\
\text { - ERN/Pe components are generated when a negative-reinforcement learning signal (i.e. failure to receive an expected reward/outcome) is conveyed to the ACC } \\
\text { via the mesencephalic dopamine system [172]. } \\
\text { - Medial prefrontal cortical (PFC) regions including the anterior cingulate cortical (ACC) regions are involved in the generation of these error-related signals } \\
\text { - Error monitoring performance using colour-naming version of the Stroop task showed ERN response was reduced in TBI subjects compared to controls [176- } \\
\text { - Ampl] } \\
\text { - Amplitude of the Pe, but not ERN, associated with decreased awareness of deficits [177] } \\
\text { - Error-related signals enhanced if participants are aware of false presses to incongruent/repeated Stroop stimuli [178]. } \\
\text { Anxiety and depression in TBI impairs performance-monitoring (181). Negative symptoms are inversely correlated with ERN amplitude i.e. emotional } \\
\text { sequelae of TBI compromise monitoring efficiency. } \\
\text { Pharmacological studies Dopamine agonists enhance error monitoring ERPs [182] The property has potential for use by the pharmacology industry eg: new/ } \\
\text { candidate medication for TBI restoring depleted dopamine may normalise ERN amplitude. }\end{array}$ \\
\hline
\end{tabular}


Miranda P (2020) Event-related-potential (ERP) markers of traumatic brain injury (TBI) severity and cognitive function - Understanding how the brain works and thinks post TBI

Table 1 Continue

Table 1. ERP markers of cognitive and social function in TBI subjects (Adapted and modified from Dockree et al. [195]

- The right inferior frontal gyrus (IFG) and the subthalamic nucleus (STN) are key players in inhibition of responses and task-sets [183,184]

- Deactivation of the pars opercularis in the right IFG impairs the ability to disengage an initiated action however the ability to initiate an action is retained [185].

- Thalamocortical output suppression is seen in top-down control processes while bottom-up stimulus-driven go/no-go tasks use midline-lateral PFC [186-188] Within healthy controls individuals who more self-rated cognitive failures rely on 'last-gasp' ACC engagement to inhibit a response while those reporting lessto-no cognitive failures had a pre-emptive 'slow-and-steady' right PFC pattern

- Shearing of white matter connectivity (prefrontal, parietal and cerebella) following TBI may cause timing deficiencies that result in a switch from predictive to a reactive mode of engagement [189]. For example if optimal timing required for PFC to integrate sensory information then the frontal regions step in reactive mode.

- Go/no-go tasks where participants must respond to every alternating stimulus but withhold to a repeated stimulus TBI subjects made more errors than controls and a speed/accuracy trade off was observed. TBI patients with faster RTs had more synchronized alpha power over mid-line fronto-central region indicating

\begin{tabular}{l|l} 
Response inhibition & $\begin{array}{l}\text { PFC down-regulation [190 8]. N2 and P } 3 \text { ERP components were reduced on no-go trials in TBI patients versus controls possibly due to loss of temporal } \\
\text { efficiency that enable timely inhibitory control. }\end{array}$
\end{tabular}

\begin{tabular}{l|l} 
Response inhibition & $\begin{array}{l}\text { PFC down-regulation [ }\left[\begin{array}{ll}190 & 8\end{array}\right] \text {. N2 and P } 3 \text { ERP components were reduced on no-go trials in TBI patients versus controls possibly due to loss of temporal } \\
\text { efficiency that enable timely inhibitory control. }\end{array}$
\end{tabular}

- Emotional responses (generated by the orbitofrontal cortex-OFC) are also inhibited in TBI patients. TBI commonly affects the anterior PFC and the OFC; failure to suppress or gate emotional reactions due to impaired OFC function could cause socially inappropriate behavior [191-195]. Patients with orbital frontal lesions show enhanced P3 in response to somatosensory and auditory stimuli compared to healthy controls and individuals with dorsolateral prefrontal lesions. Habituation to stimuli was also lost in subjects with OFC lesions [192].

- Failure of evaluative and regulatory mechanisms (switching between different instructional task-sets during a cued Stroop colour-word task) may be the reason flexible deployment of attention in TBI subjects is impaired [125].

- TBI subjects were less able to efficiently detect colour-word conflict and under incongruent conditions did not produce a fronto-central N450 seen in controls and source-localized to the ACC [174].

- The centro-parietal conflict slow potential (conflict SP) elicited using incongruent Stroop trials is reduced in controls and not reduced in severe TBI subjects this could account for their lack of flexibility during conflict [193].

- The N400, P600, Left Anterior Negativity (LAN) and Mismatch Negativity (MMN) are ERP components used in language research [196-201].

- When subjects evaluate word pairs that facilitate retrieval compared with responses elicited by word pairs that do not facilitate retrieval a 750msec ERP is elicited located at the left fronto-temporal region [197].

Word Retrieval and Language

- A study investigated the neurophysiological correlates of word retrieval networks in 19 retired professional athletes with TBI and 19 healthy control (HC) subjects [197]. There were no significant differences in accuracy or RT between the two groups. The EEG showed a significant group by condition interaction over the left fronto-temporal region. The HC group mean amplitudes were significantly different between conditions, but the TBI group data did not show this difference, suggesting neurophysiological effects of injury.

Table 2. EEG studies on mTBI and conditions also exhibiting similar EEG patterns. Adapted and modified from Rapp et al. [45]. \#Adapted and modified from Bonita et al. [231]

\begin{tabular}{|c|c|c|c|c|}
\hline \multirow{9}{*}{$\begin{array}{c}\text { EEG Spectral Power } \\
{[202-208]}\end{array}$} & \multirow{3}{*}{$\begin{array}{c}\text { Frequency range } \\
\text { Delta }\end{array}$} & \multicolumn{3}{|c|}{ mTBI and Spectral power } \\
\hline & & Decrease & Increase & Unchanged \\
\hline & & Tebano et al. & Korn et al. & \\
\hline & Theta & & Tomkins et al. & Tebano et al. \\
\hline & Alpha & Korn et al., Gosselin et al. & Tebano et al. & $\begin{array}{l}\text { Chen et al. } \\
\text { Tebano et al. }\end{array}$ \\
\hline & Beta & Tebano et al. & Thornton & $\begin{array}{l}\text { Tebano et al. } \\
\text { Chen et al. }\end{array}$ \\
\hline & \multicolumn{4}{|l|}{ Gamma } \\
\hline & Theta/alpha & Chen et al. & Watson et al., Chen et al. & \\
\hline & Alpha1/alpha2 & & Chen et al. & \\
\hline $\begin{array}{c}\text { Synchronization of EEGs } \\
{[158,190,209-216]}\end{array}$ & \multicolumn{4}{|c|}{$\begin{array}{l}\text { TBI studies altered synchronization of EEGs } \\
\text { Dockree } \text { et al. 2004, Hoffman et al. 1995, Kumar et al. 2009a,b, Roche } \text { et al. 2004, Slewa-Younan et al. 2002, Thatcher } \text { et al. 1999, } \\
\text { 2000, 2001, 2006 } \\
\text { Neuropsychiatric disorders that also exhibit altered synchronization of EEGs } \\
\text { AD/HD, Alcohol abuse, Alexithymia, Autism, Bipolar disorders, Dementia, Depression, Hallucinations, HIV dementia, Migraine, Multiple } \\
\text { sclerosis, Neuropsychiatric disorders: general reviews, Parkinson's disease, Post-traumatic stress disorder, Schizophrenia and other psychotic } \\
\text { disorders }\end{array}$} \\
\hline $\begin{array}{c}\text { Functional connectivity } \\
\# \\
{[204,211,212,217-226]}\end{array}$ & \multicolumn{4}{|c|}{$\begin{array}{l}\text { mTBI and Altered functional connectivity } \\
\text { Cao and Slobounov 2010, Kumar et al. 2009a,b, Castellanos et al. 2010, 2011a,b Nakamura et al. 2009, Ham and Sharp 2012, Sponheim et } \\
\text { al. } 2011 \text {, Kasahara et al. 2010, Tsirka et al. 2011, Thatcher et al 1991, Thornton } 2003 \\
\text { Pathological conditions also associated with altered functional connectivity } \\
\text { Alzheimer's disease, Epileptic seizures, Intra-arterial amobarbital injection, Autism spectrum disorder, Brain tumors, Multiple sclerosis, } \\
\text { Preterm birth, Post traumatic stress disorder (PTSD), Schizophrenia, Stroke. }\end{array}$} \\
\hline $\begin{array}{l}\text { Network Geometries } \\
{[217-221,225,227-230]}\end{array}$ & \multicolumn{4}{|c|}{$\begin{array}{l}\text { TBI studies showing altered network geometries: } \\
\text { Cao and Slobounov, 2010, Castellanos et al., 2010, 2011a,b, Nakamura et al., 2009, Tsirka et al., 2011, Zourdakis et al., 2011, Irimia et al., } \\
\text { 2013a, b, Goh et al. 2014, } \\
\text { Neuropsychiatric disorders also exhibiting altered network geometries } \\
\text { Alzheimer's disease, CNS tumor, Depression, Epilepsy, Schizophrenia }\end{array}$} \\
\hline
\end{tabular}


Miranda P (2020) Event-related-potential (ERP) markers of traumatic brain injury (TBI) severity and cognitive function - Understanding how the brain works and thinks post TBI

\section{References}

1. Kim E, Lauterbach EC, Reeve A (2007) Neuropsychiatric complications of traumatic brain injury: a critical review of the literature (a report by the ANPA Committee on Research). J Neuropsychiatry Clin Neurosci 19: 106-127.

2. Van Reekum R, Cohen T, Wong J (2000) Can traumatic brain injury cause psychiatric disorders? J Neuropsychiatry Clin Neurosci 12: 316-327.

3. Hibbard MR, Uysal S, Kepler K (1998) Axis I psychopathology in individuals with traumatic brain injury. J Head Trauma Rehabil 13: 24-39.

4. Deb S, Lyons I, Koutzoukis C (1999) Rate of psychiatric illness 1 year after traumatic brain injury. Am J Psychiatry 156: 374-378.

5. Bryant RA, Marosszeky JE, Crooks J (2000) Posttraumatic stress disorder after severe traumatic brain injury. Am J Psychiatry 157: 629-631.

6. Glaesser J, Neuner F, Lütgehetmann R (2004) Posttraumatic stress disorder in patients with traumatic brain injury. BMC Psychiatry 4: 5

7. Kreutzer JS, Seel RT, Gourley E (2001) The prevalence and symptom rates of depression after traumatic brain injury: a comprehensive examination. Brain Inj 15: $563-576$

8. Jorge RE, Starkstein SE, Arndt S (2005) Alcohol misuse and mood disorders following traumatic brain injury. Arch Gen Psychiatry 62: 742-749.

9. Pelegrín-Valero CA, Gómez-Hernández R, Muñoz-Céspedes JM (2001) Nosologic aspects of personality change due to head trauma. Rev Neurol 32: 681-687.

10. Zeilig G, Drubach DA, Katz-Zeilig M (1996) Pathological laughter and crying in patients with closed traumatic brain injury. Brain Inj 10: 591-597.

11. Tateno A, Jorge RE, Robinson RG (2003) Clinical correlates of aggressive behavior after traumatic brain injury. J Neuropsychiatry Clin Neurosci 15: 155-160.

12. Tateno A, Jorge RE, Robinson RG (2004) Pathological laughing and crying following traumatic brain injury. J Neuropsychiatry Clin Neurosci 16: 426-34.

13. Levin HS, McCauley SR, Josic CP (2005) Predicting depression following mild traumatic brain injury. Arch Gen Psychiatry 62: 523-528.

14. Jorge RE, Acion L, Starkstein SE (2007) Hippocampal volume and mood disorders after traumatic brain injury. Biol Psychiatry 62: 332-338.

15. Jorge RE, Robinson RG, Moser D (2004) Major depression following traumatic brain injury. Arch Gen Psychiatry 61: 42-50.

16. Fedoroff JP, Starkstein SE, Forrester AW (1992) Depression in patients with acute traumatic brain injury. Am J Psychiatry 149: 918-923.

17. Jorge RE, Robinson RG, Starkstein SE (1993) Secondary mania following traumatic brain injury. Am J Psychiatry 150: 916-921.

18. Murai T, Fujimoto S (2003) Rapid cycling bipolar disorder after left temporal pola damage. Brain Inj 17: 355-358.

19. Shukla S, Cook BL, Mukherjee S (1987) Mania following head trauma. Am J Psychiatry 144: 93-96.

20. Berthier ML, Kulisevsky JJ, Gironell A (2001) Obsessive-compulsive disorder and traumatic brain injury: behavioral, cognitive, and neuroimaging findings. Neuropsychiatry Neuropsychol Behav Neurol 14: 23-31.

21. Bilgic B, Baral-Kulaksizoglu I, Hanagasi H (2004) Obsessive-compulsive disorder secondary to bilateral frontal damage due to a closed head injury. Cogn Behav Neurol 17: $118-120$.

22. Ogai M, Iyo M, Mori N (2005) A right orbitofrontal region and OCD symptoms: a case report. Acta Psychiatr Scand 111: 74-76.

23. Sojka P, Stalnacke BM, Björnstig U (2006) One-year follow-up of patients with mild traumatic brain injury: occurrence of post-traumatic stress-related symptoms at followup and serum levels of cortisol, S-100B and neuron-specific enolase in acute phase. Brain Inj 20: 613-20.

24. Achte KA, Hillbom E, Aalberg V (1969) Psychoses following war brain injuries. Acto Psychiatr Scand 45: 1-18.

25. Sachdev P, Smith JS, Cathcart S (2001) Schizophrenia-like psychosis following traumatic brain injury: a chart-based descriptive and case-control study. Psychol Med 31: 231-239.

26. Fujii D, Ahmed I (2002) Characteristics of psychotic disorder due to traumatic brain injury: an analysis of case studies in the literature. J Neuropsychiatry Clin Neurosci 14: $130-140$.
27. Fujii D, Ahmed I, Hishinuma E (2004) A neuropsychological comparison of psychotic disorder following traumatic brain injury, traumatic brain injury without psychotic disorder, and schizophrenia. J Neuropsychiatry Clin Neurosci 16: 306-314.

28. Fujii D, Ahmed I (2004) Is psychosis a neurobiological syndrome? Can J Psychiatry 49: 713-718.

29. Wilde EA, Bigler ED, Gandhi PV (2004) Alcohol abuse and traumatic brain injury: quantitative magnetic resonance imaging and neuropsychological outcome. $J$ Neurotrauma 21: 137-147.

30. Kreutzer JS, Witol AD, Marwitz JH (1996) Alcohol and drug use among young persons with traumatic brain injury. J Learn Disabi 29: 643-651.

31. Ponsford J, Whelan-Goodinson R, Bahar-Fuchs A (2007) Alcohol and drug use following traumatic brain injury: a prospective study. Brain Inj 21: 1385-1392.

32. Andersson S, Krogstad JM, Finset A (1999) Apathy and depressed mood in acquired brain damage: relationship to lesion localization and psychophysiological reactivity. Psychol Med 29: 447-56.

33. Robinson RG, Parikh RM, Lipsey JR (1993) Pathological laughing and crying following stroke: validation of a measurement scale and a double-blind treatment study. Am J Psychiatry 150: 286-93.

34. Grafman J, Schwab K, Warden D (1996) Frontal lobe injuries, violence, and aggression: a report of the Vietnam Head Injury Study. Neurology 46: 1231-1238.

35. Diaz AP, Schwarzbold ML, Thais ME, Hohl A, Bertotti MM, et al. (2012) Psychiatric disorders and health-related quality of life after severe traumatic brain injury: a prospective study. J Neurotrauma 29: 1029-1037.

36. Uryu K, Chen X-H, Martinez D, Browne KD, Johnson VE, et al. (2007) Multiple proteins implicated in neurodegenerative diseases accumulate in axons after brain trauma in humans. Exp Neurol 208: 185-192.

37. Gardner RC, Yaffe K (2015) Epidemiology of mild traumatic brain injury and neurodegenerative disease. Mol Cell Neurosci 66: 75-80.

38. Goldman SM, Tanner CM, Oakes D, Bhudhikanok GS, Gupta A, et al. (2006) Head injury and Parkinson's disease risk in twins. Ann Neurol 60: 65-72

39. Chen H, Richard M, Sandler DP, Umbach DM, Kamel F, et al. (2007) Head injury and amyotrophic lateral sclerosis. Am J Epidemiol 166: 810-816.

40. Singh, R, Turner RC, Nguyen L, Motwani K, Swatek M, et al. (2016) Pediatric Traumatic Brain Injury and Autism: Elucidating Shared Mechanisms. Behavioural neurology 8781725 .

41. Adeyemo BO, Biederman J, Zafonte R, Kagan E, Spencer TJ, et al. (2014) Mild traumatic brain injury and ADHD: A systematic review of the literature and metaanalysis. J Atten Disord 18: 576-584.

42. Biederman J, Feinberg L, Chan J, Adeyemo BO, Woodworth KY, et al. (2015) Mild Traumatic Brain Injury and Attention-Deficit Hyperactivity Disorder in Young Student Athletes. The Journal of nervous and mental disease 203: 813-819.

43. Molloy C, Conroy RM, Cotter DR, Cannon M (2011) Is traumatic brain injury a risk factor for schizophrenia? A meta-analysis of case-controlled population-based studies. Schizophrenia bulletin 37: 1104-1110.

44. Englander J, Cifu DX, Diaz-Arrastia R (2014) Information/education page. Seizures and traumatic brain injury. Archives of physical medicine and rehabilitation $95: 1223$ 1224.

45. Schwarzbold M, Diaz A, Martins ET, Rufino A, Amante LN, et al. (2008) Psychiatric disorders and traumatic brain injury. Neuropsychiatric disease and treatment 4: 797 816.

46. Rapp PE, Keyser DO, Albano A, Hernandez R, Gibson DB, et al. (2015) Traumatic brain injury detection using electrophysiological methods. Frontiers in human neuroscience 9: 11.

47. Meng Q, Zhuang Y, Ying Z, Agrawal R, Yang X, et al. (2017) Traumatic Brain Injury Induces Genome-Wide Transcriptomic, Methylomic, and Network Perturbations in Brain and Blood Predicting Neurological Disorders. EBioMedicine 16: 184-194.

48. Masterson C (2019) Neurophysiological Alterations Following Concussion: Controlling for the Injury Factor". Theses, Dissertations, and Student Research: Department of Psychology 115

49. Centers for Disease Control and Prevention (2017) What are the signs and symptoms of concussion? Retrieved from https://www.cdc.gov/traumaticbraininjury/symptoms html. 
Miranda P (2020) Event-related-potential (ERP) markers of traumatic brain injury (TBI) severity and cognitive function - Understanding how the brain works and thinks post TBI

50. National Institute of Neurological Disorders and Stroke (2018) Traumatic brain injury information page. Retrieved from https://www.ninds.nih.gov/disorders/all-disorders/ traumatic-brain-injury-information-page.

51. Blakely TA Jr, Harrington DE (1993) Mild head injury is not always mild; implications for damage litigation. Med Sci Law 33: 231-242.

52. Gaetz M, Bernstein DM (2001) The current status of electrophysiologic procedures for the assessment of mild traumatic brain injury. Journal of Head Trauma Rehabilitation 16: 386-405.

53. Mathias JL, Beall JA, Bigler ED (2004) Neuropsychological and information processing deficits following mild traumatic brain injury. Journal of the International Neuropsychological Society 10: 286-297.

54. Mathias JL, Wheaton $P$ (2007) Changes in attention and information-processing speed following severe traumatic brain injury: A meta-analytic review. Neuropsychology 21: 212-223.

55. Tulsky DS, Carlozzi NE, Holdnack J, Heaton RK, Wong A, et al. (2017) Using the NIH Toolbox Cognition Battery (NIHTB-CB) in individuals with traumatic brain injury Rehabilitation Psychology 4: 413-424.

56. Benedict RHB (1997) Brief visuospatial memory test - Revised, Lutz, FL: Psychological Assessment Resources.

57. Delis DC, Kaplan E, Kramer J (2001) Delis Kaplan Executive Function System, San Antonio, TX: The Psychological Corporation.

58. Gronwall DM (1977) Paced auditory serial-addition task: A measure of recovery from concussion. Perceptual \& Motor Skills 44: 367-373.

59. Heaton S.K, Chelune GJ, Talley JL, Kay GG, Curtiss G, et al. (1993) Wisconsin card sorting test manual: Revised and expanded, Odessa, FL: Psychological Assessment Resources.

60. Shallice T (1982) Specific impairments of planning. Philosophical Transactions of the Royal Society of London Series B: Biological Sciences 298: 199-209.

61. Wechsler D, Coalson DL, Raiford SE (2008) WAIS-IV technical and interpretive manual, San Antonio, TX: Pearson

62. Kraus N, White-Schwoch T (2015) Unraveling the biology of auditory learning: A cognitive-sensorimotor-reward framework. Trends in Cognitive Sciences 19: 642-654.

63. Washnik NJ, Anjum J, Lundgren K, Phillips S (2019) A Review of the Role of Auditory Evoked Potentials in Mild Traumatic Brain Injury Assessment. Trends Hear 23: 2331216519840094.

64. Gallun FJ, Diedesch AC, Kubli LR, Walden TC, Folmer RL, et al. (2012) Performance on tests of central auditory processing by individuals exposed to high-intensity blasts. Journal of Rehabilitation Research and Development 49: 1005-1025.

65. Noseworthy JH, Miller J, Murray TJ, Regan D (1981) Auditory brainstem responses in postconcussion syndrome. Archives of Neurology 38: 275-278.

66. Podoshin L, Ben-David J, Fradis M, Pratt H (1990) Brainstem auditory evoked potentials with increased stimulus rate in minor head trauma. The Journal of Laryngology and Otology 49: 287-293.

67. Kraus N, Thompson EC, Krizman J, Cook K, White-Schwoch T, et al. (2016) Auditory biological marker of concussion in children. Scientific Reports 6: 39009

68. Munjal SK, Panda NK, Pathak A (2010) Relationship between severity of traumatic brain injury (TBI) and extent of auditory dysfunction. Brain Injury 24: 525-532.

69. Soustiel J.F, Hafner H, Chistyakov A.V, Barzilai A, Feinsod M, et al. (1995) Trigeminal and auditory evoked responses in minor head injuries and post-concussion syndrome. Brain Injury 9: 805-813.

70. Drake ME, Weate SJ, Newell SA (1996) Auditory evoked potentials in postconcussive syndrome. Electromyography and Clinical Neurophysiology 36: 457-462.

71. Arciniegas D, Olincy A, Topkoff J, Mcrae K, Cawthra E, et al. (2000) Impaired auditory gating and $\mathrm{p} 50$ nonsuppression following traumatic brain injury. The Journal of Neuropsychiatry and Clinical Neurosciences 12: 77-85.

72. Gosselin N, Thériault M, Leclerc S, Montplaisir J, Lassonde M, et al. (2006) Neurophysiological anomalies in symptomatic and asymptomatic concussed athletes. Neurosurgery 58: 1151-1161.

73. Solbakk A, Reinvang I, Nielsen C, Sundet K (1999) ERP indicators of disturbed attention in mild closed head injury: A frontal lobe syndrome? Psychophysiology 36: 802-817.

74. Pratap-Chand R, Sinniah M, Salem FA (1988) Cognitive evoked potential (P300): A metric for cerebral concussion. Acta Neurologica Scandinavica 78: 185-189.
75. Segalowitz SJ, Bernstein DM, Lawson S (2001) P300 event-related potential decrements in well-functioning university students with mild head injury. Brain and Cognition 45: 342-356.

76. Thériault M, Beaumont LD, Gosselin N, Filipinni M, Lassonde M (2009) Electrophysiological abnormalities in well-functioning multiple concussed athletes. Brain Injury 23: 899-906.

77. Nandrajog P, Idris Z, Azlen WN, Liyana A, Abdullah JM, et al. (2017) The use of event-related potential (P300) and neuropsychological testing to evaluate cognitive impairment in mild traumatic brain injury patients. Asian J Neurosurg 12: 447-453.

78. De Beaumont L, Théoret H, Mongeon D, Messier J, Leclerc S, et al. (2009) Brain function decline in healthy retired athletes who sustained their last sports concussion in early adulthood. Brain 132: 695-708.

79. Potter DD, Bassett MRA, Jory SH, Barrett K (2001) Changes in event-related potentials in a three-stimulus auditory oddball task after mild head injury. Neuropsychologia 39 . 1464-1472.

80. Vander Werff KR and Rieger B (2017) Brainstem evoked potential indices of subcortical auditory processing after mild traumatic brain injury. Ear Hear 38: e200-e214.

81. Al-Hady MA, Shehata O, El-Mously M (1990) Audiological findings following head trauma. J Laryngol Otol 104: 927-936.

82. Benna P, Bergamasco B, Bianco C (1982) Brainstem auditory evoked potentials in postconcussion syndrome. Ital J Neurol Sci 3: 281-287. 24.

83. Averaging EP (1981) Auditory brainstem responses in postconcussion syndrome. Arch Neurol 38: 275-278.

84. Rowe MJ and Carlson C (1980) Brainstem auditory evoked potentials in postconcussion dizziness. Arch Neurol 37: 679-683.

85. Nolle C, Todt I, Seidl RO (2004) Pathophysiological changes of the central auditory pathway after blunt trauma of the head. J Neurotrauma 21: 251-258.

86. Haglund $Y$ and Persson HE (1990) Does Swedish amateur boxing lead to chronic brain damage? 3. A retrospective clinical neurophysiological study. Acta Neurol Scand 82 $353-360$.

87. Geets W (1985) EEG and brainstem abnormalities after cerebral concussion. Short term observations. Acta Neurol Belg 85: 277-283.

88. Schoenhuber R, Bortolotti P, Malavasi P (1983) Brain stem auditory evoked potentials in early evaluation of cerebral concussion. J Neurosurg Sci 27: 157-159.

89. Schoenhuber R, Gentilini M, Orlando A (1988) Prognostic value of auditory brain-stem responses for late postconcussion symptoms following minor head injury. $J$ Neurosurg 68: $742-744$.

90. Schoenhuber R and Gentilini M (1986) Auditory brain stem responses in the prognosis of late postconcussional symptoms and neuropsychological dysfunction after minor head injury. Neurosurgery 19: 532-534

91. Papathanasiou ES, Cronin T, Seemungal B, Sandhu J (2018) Electrophysiological testing in concussion: A guide to clinical applications. J Concussion 2: 205970021881263.

92. Gomes J, Damborská A (2017) Event-Related Potentials as Biomarkers of Mild Traumatic Brain Injury. Act Nerv Super 59 87-90.

93. Ciuffreda K, Kapoor N (2012) Acquired brain injury. In: Taub MB, Bartuccio M, Maino DM, editors. eds. Visual Diagnosis and Care of the Patient with Special Needs, Philadelphia, PA: Wolters Kluwer Health/Lippincott Williams \& Wilkins.

94. Ciuffreda KJ, Kapoor N, Rutner D (2007) Occurrence of oculomotor dysfunctions in acquired brain injury: a retrospective analysis. Optometry 78: 155-161.

95. Covassin T, Elbin RJ (2010) The cognitive effects and decrements following concussion. Open Access J Sports Med 1: 55-61.

96. Cohen M, Groswasser Z, Barchadski R (1989) Convergence insufficiency in braininjured patients. Brain Inj 3: 187-191.

97. Thiagarajan P, Ciuffreda K (2014) Accommodative and vergence dysfunctions in mTBI: treatment effects and systems correlations. Optom Visual Perform 2: 281-288.

98. Ciuffreda KJ, Tannen B (1995) Eye Movement Basics for the Clinician. St. Louis, MO Mosby-Year Book, Inc.

99. Thiagarajan P, Ciuffreda KJ (2014) Versional eye tracking in mild traumatic brain injury (mTBI): effects of oculomotor training (OMT). J Rehabil Res Dev 28: 930-943.

100. Ciuffreda KJ, Kapoor N, Rutner D, Suchoff IB, Han ME, et al. (2007) Occurrence of oculomotor dysfunctions in acquired brain injury: a retrospective analysis. Optometry 78: $155-161$. 
Miranda P (2020) Event-related-potential (ERP) markers of traumatic brain injury (TBI) severity and cognitive function - Understanding how the brain works and thinks post TBI

101. Green W, Ciuffreda KJ, Thiagarajan P, Szymanowicz D, Ludlam DP, et al. (2010) Accommodation in mild traumatic brain injury. J Rehabil Res Dev 47: 183-200.

102. Truong J, Ciuffreda K, Han M, Suchoff I (2014) Photosensitivity in mild traumatic brain injury (mTBI): a retrospective analysis. Brain Inj 28: 1283-1287.

103. Zihl J (2010) Rehabilitation of Visual Disorders After Brain Injury. New York, NY: Psychology Press 288.

104. Werner RA, Vanderzant CW (1991) Multimodality evoked potential testing in acute mild closed head injury. Arch Phys Med Rehabil 72: 31-34.

105. Papathanasopoulos P, Konstantinou D, Flaburiari K, et al. (1994) Pattern reversal visual evoked potentials in minor head injury. Eur Neurol 34: 268-271.

106. Gaetz M, Weinberg H (2000) Electrophysiological indices of persistent postconcussion symptoms. Brain Injury 14: 815-832.

107. Moore RD, Broglio SP, Hillman CH (2014) Sport-related concussion and sensory function in young adults. $J$ Athletic Train 49: 36-41.

108. Fimreite V, Ciuffreda KJ, Yadav NK (2015) Effect of luminance on the visuallyevoked potential in visuallynormal individuals and in mTBI/concussion. Brain Injury 29: 1199-1210.

109. Yadav N, Ciuffreda K (2015) Objective assessment of visual attention in mild traumatic brain injury (mTBI) using visual-evoked potentials (VEP). Brain Injury 29: $352-365$.

110. Fimreite V, Willeford KT, Ciuffreda KJ (2016) Effect of chromatic filters on visua performance in individuals with mild traumatic brain injury (mTBI): A pilot study. Journal of optometry 9: 231-239.

111. Lachapelle J, Ouimet C, Bach M (2004) Texture segregation in traumatic brain injury - a VEP study. Vis Res 44: 2835-2842.

112. Poltavski D, Lederer P, Cox LK (2017) Visually evoked potential markers of concussion history in patients with convergence insufficiency. Optom Vis Sci 94: 742.

113. Boutin D, Lassonde M, Robert M (2008) Neurophysiological assessment prior to and following sports-related concusssion during childhood: a case study. Neurocase 14: $239-248$.

114. Broglio SP (2009) The persistent effects of concussion on neuroelectric indices ofattention. Journal of Neurotrauma 26: 1463 -1470.

115. Gosselin N (2011) Electrophysiology and functional MRI in post-acute mild traumatic brain injury. Journal of Neurotrauma 28329 -341.

116. Gosselin N (2012) Evaluating the cognitive consequences of mild traumatic brain injury and concussion by using electrophysiology. Neurosurgical Focus 33: E7

117. Lachapelle J, Bolduc-Teasdale J, Ptito A, McKerral M (2008) Deficits in complex visual information processing after mild TBI: electrophysiological markers and vocational outcome prognosis. Brain Injury 22: 265-274.

118. DiRusso F, Spinelli D (2010) Sport is not always healthy: executive brain dysfunction in professional boxers. Psychophysiology 47: 425-434.

119. Dupuis F, Johnston KM, Lavoie M, Lepore F, Lassonde M et al. (2000) Concussions in athletes produce brain dysfunction as revealed by event-related potentials. Neuroreport 11: 4087 -4092.

120. Li L (2016) Brain activation profiles in mTBI: evidence from ERP activity of working memory response. Paper presented at the Proceedings of the Annual International Conference of the IEEE Engineering in Medicine and Biology Society, EMBS 3. 1862-1865.

121. Potter DD (2002) Effect of mild head injury on event-related potential correlates of Stroop task performance. Journal of the International Neuropsychological Society 8: 828-837.

122. Larson MJ, Farrer TJ, Clayson PE (2011) Cognitive control in mild traumatic brain injury: conflict monitoring and conflict adaptation. International Journal of Psychophysiology 82: 69 -78.

123. Larson MJ, Clayson PE, Farrer TJ (2012) Performance monitoring and cognitive controlin individuals with mild traumatic brain injury. Journal of the International Neuropsychological Society 18: 323-333.

124. Wolf JA, Koch PF. Disruption of network synchrony and cognitive dysfunction after traumatic brain injury. Front Syst Neurosci 43: 1-14

125. Witgen BM, Lifshitz J, Smith ML (2005) Regional hippocampal alteration associated with cognitive deficit following experimental brain injury: a systems, network and cellular evaluation. Neuroscience 133: 1-15.
126. Larson MJ, Kaufman DA, Kellison IL (2009) Double jeopardy! The additive consequences of negative affect on performance-monitoring decrements following traumatic brain injury. Neuropsychology 23: 433-444.

127. Perlstein WM, Larson MJ, Dotson VM (2006) Temporal dissociation of components of cognitive control dysfunction in severe TBI: ERPs and the cued-Stroop task Neuropsychologia 44: 260-274.

128. Yu Z, Morrison BR (2010) Experimental mild traumatic brain injury induces functional alteration of the developing hippocampus. J Neurophysiol 103: 499-510.

129. Chen AJ, D'Esposito M (2010) Traumatic brain injury: from bench to bedside [corrected] to society. Neuron 66: 11-14.

130. Lew HL, Poole JH, Chiang JY (2005) Event-related potential in facial affect recognition: potential clinical utility in patients with traumatic brain injury. $J$ Rehabil Res Dev 42: 29-34

131. Green L, Godfrey C, Soo C (2013) A preliminary investigation into psychosocia outcome and quality-of-life in adolescents following childhood traumatic brain injury. Brain Inj 27: 872-877.

132. Bogart E, Togher L, Power E (2012) Casual conversations between individuals with traumatic brain injury and their friends. Brain Inj 26: 221-233.

133. Ferraro FR (1996) Cognitive slowing in closed-head injury. Brain Cogn 32: 429-440

134. Lam CS (1988) Deficit awareness and treatment performance among traumatic head injury adults. Brain Inj 2: 235-242.

135. Sherer M (1998) The Awareness Questionnaire: factor structure and internal consistency. Brain Inj 12: 63-68.

136. Wise K (2005) Convergent validity of self-awareness measures and their association with employment outcome in adults following acquired brain injury. Brain Inj 19: 765-775.

137. Trudel T, Tryone W, Purdum C (1998) Awareness of disability and long-term outcome after traumatic brain injury. Rehabilitation Psychology 43: 267-281.

138. Prigatano G, Fordyce D (1986) Cognitive dysfunction and psychosocial adjustmen after brain injury. Baltimore: John Hopkins University Press.

139. Ylvisaker M (1986) Language and communication disorders following pediatric head injury. J Head Trauma Rehabil 1: 48-56.

140. King KA, Hough MS, Walker MM, Rastatter M, Holbert D (2006) Mild traumatic brain injury: effects on naming in word retrieval and discourse. Brain Inj 20: 725-732.

141. McWilliams J, Schmitter-Edgecombe M (2008) Semantic memory organization during the early stage of recovery from traumatic brain injury. Brain Inj 22: 243-253.

142. Hart J (2013) Semantic memory retrieval circuit: role of pre-SMA, caudate, and thalamus. Brain Lang 126: 89-98.

143. Shah SA (2017) Executive attention deficits after traumatic brain injury reflect impaired recruitment of resources. NeuroImage Clinical 14: 233-241.

144. Hauger SL (2017) Cognitive Event-Related Potentials during the Sub-Acute Phase of Severe Traumatic Brain Injury and Their Relationship to Outcome. J Neurotrauma 34: 3124-3133.

145. Arakaki X (2018) Alpha desynchronization/synchronization during working memory testing is compromised in acute mild traumatic brain injury (mTBI). PloS one 13 e0188101.

146. Galetto V, Sacco K (2017) Neuroplastic Changes Induced by Cognitive Rehabilitation in Traumatic Brain Injury: A Review. Neurorehabil Neural Repair 31: 800-813.

147. Porter S (2017) Changes in brain-behavior relationships following a 3-month pilot cognitive intervention program for adults with traumatic brain injury. Heliyon 3 : e00373.

148. Felmingham KL (2004) Effects of diffuse axonal injury on speed of information processing following severe traumatic brain injury. Neuropsychology 18: 564571.

149. Reinvang I (2000) Information processing deficits in head injury assessed with ERPs reflecting early and late processing stages. Neuropsychologia 38: 995-1005.

150. Heinze HJ (1992) Parallel and serial visual search after closed head injury: electrophysiological evidence for perceptual dysfunctions. Neuropsychologia 30 : $495-514$

151. Campbell KB (1990) Electrophysiological assessment of cognitive disorder in closed head-injured outpatients. Electroencephalogr Clin Neurophysiol 41: 202-215. 
Miranda P (2020) Event-related-potential (ERP) markers of traumatic brain injury (TBI) severity and cognitive function - Understanding how the brain works and thinks post TBI

152. Cremona-Meteyard SL (1994) Event-related potential indices of visual attention following moderate to severe closed head injury. Brain Inj 8: 541-558.

153. Segalowitz SJ (1997) Attentional factors in response time variability after traumatic brain injury: an ERP study. J Int Neuropsychol Soc 3: 95-107.

154. Segalowitz SJ (1992) CNV evidence for the distinctiveness of frontal and posterior neural processes in a traumatic brain-injured population. J Clin Exp Neuropsychol 14: 545-565.

155. Rugg MD (1989) CNV abnormalities following closed head injury Brain 112: 489506.

156. Deacon D (1991) Decision-making following closed-head injury: can response speed be retrained? J Clin Exp Neuropsychol 13: 639-651.

157. Stuss DT (2003) Staying on the job: the frontal lobes control individual performance variability. Brain 126: 2363-2380.

158. Dockree PM (2006) Sustained attention in traumatic brain injury (TBI) and healthy controls: enhanced sensitivity with dual-task load. Exp Brain Res 168: 218-229.

159. Lutz A (2009) Mental training enhances attentional stability: neural and behavioral evidence. J Neurosci 29: 13418-13427.

160. Dockree PM (2004) Behavioural and physiological impairments of sustained attention after traumatic brain injury. Brain Res Cogn Brain Res 20: 403-414.

161. Dockree PM (2005) Neurophysiological markers of alert responding during goaldirected behavior: A high-density electrical mapping study. Neuroimage 27: 587-601.

162. O'Connell RG (2009) Uncovering the neural signature of lapsing attention: electrophysiological signals predict errors up to $20 \mathrm{~s}$ before they occur. $J$ Neurosci 29: 8604-8611.

163. O'Connell RG (2010) Tracing the neural signature of lapsing attention in the preerror period using simultaneous EEG and fMRI. Paper presented at the 20th Annual Rotman Research Institute Conference: The Frontal Lobes.

164. Sonuga-Barke EJ (2007) Spontaneous attentional fluctuations in impaired states and pathological conditions: a neurobiological hypothesis. Neurosci Biobehav Rev 31: 977986.

165. O'Connell RG (2004) Reduced electrodermal response to errors predicts poor sustained attention performance in attention deficit hyperactivity disorder. Neuroreport 15: 2535-2538.

166. O'Connell RG (2008) SelfAlert Training: volitional modulation of autonomic arousa improves sustained attention. Neuropsychologia 46: 1379-1390.

167. O'Keeffe F (2006) Awareness of Deficits in Traumatic Brain Injury: A Multidimensional Approach to Assessing Metacognitive Knowledge and OnlineAwareness. Journal of the International Neuropsychological Society.

168. O'Keeffe F (2004) Poor insight in traumatic brain injury mediated by impaired error processing? Evidence from electrodermal activity. Brain Res Cogn Brain Res 22: 101-112.

169. Dockree PM (2006) Capture by misleading information and its false acceptance in patients with traumatic brain injury. Brain 129: 128-140.

170. Frank MJ (2007) Cross-task individual differences in error processing: neural, electrophysiological, and genetic components. Cogn Affect Behav Neurosci 7: 297308 .

171. Franken IH (2007) Error-processing deficits in patients with cocaine dependence. Biol Psychol 75: 45-51.

172. Falkenstein M (2000) ERP components on reaction errors and their functional significance: a tutorial. Biol Psychol 51: 87-107.

173. Boksem MA (2008) Sensitivity to punishment and reward omission: evidence from error-related ERP components. Biol Psychol 79: 185-192.

174. Holroyd CB (2002) The neural basis of human error processing: reinforcement learning, dopamine, and the error-related negativity. Psychol Rev 109: 679-709.

175. Carter CS (2007) Anterior cingulate cortex and conflict detection: an update of theory and data. Cogn Affect Behav Neurosci 7: 367-379.

176. Van Veen V (2002) The timing of action-monitoring processes in the anterior cingulate cortex. J Cogn Neurosci 14: 593-602.

177. Nieuwenhuis S (2001) Error-related brain potentials are differentially related to awareness of response errors: evidence from an antisaccade task. Psychophysiology 38: $752-760$.
178. O'Connell RG (2007b) The role of cingulate cortex in the detection of errors with and without awareness: a high-density electrical mapping study. Eur J Neurosci 25 : 2571-2579.

179. Hester R (2005) Neural mechanisms involved in error processing: a comparison of errors made with and without awareness. Neuroimage 27: 602-608.

180. O'Connell RG (2007a) The role of cingulate cortex in the detection of errors with and without awareness: a high-density electrical mapping study. Eur J Neurosci 25 : 2571-2579.

181. Larson MJ (2007) Performance monitoring, error processing, and evaluative control following severe TBI. J Int Neuropsychol Soc 13: 961971.

182. Larson MJ (2009) Awareness of deficits and error processing after traumatic brain injury. Neuroreport 20: 1486-1490.

183. Larson MJ (2009) Double jeopardy! The additive consequences of negative affect on performance-monitoring decrements following traumatic brain injury. Neuropsychology 23: 433-444.

184. De Bruijn ER (2004) Drug-induced stimulation and suppression of action monitoring in healthy volunteers. Psychopharmacology 177: 151-160.

185. Aron AR (2004) Inhibition and the right inferior frontal cortex. Trends Cogn Sci 8 170-177.

186. Aron AR (2006) Cortical and subcortical contributions to Stop signal response inhibition: role of the subthalamic nucleus. J Neurosci 26: 2424-2433.

187. Chambers CD (2006) Executive "brake failure" following deactivation of human frontal lobe. J Cogn Neurosci 18: 444-455

188. Fassbender C (2009) Prefrontal and midline interactions mediating behavioural control. Eur J Neurosci 29: 181-187.

189. Fassbender C (2004) A topography of executive functions and their interaction revealed by functional magnetic resonance imaging. Brain Res Cogn 20: 132-143.

190. Garavan H (2002) Dissociable executive functions in the dynamic control of behavior: inhibition, error detection, and correction. Neuroimage 17: 1820-1829

191. Ghajar J, Ivry RB (2008) The predictive brain state: timing deficiency in traumatic brain injury? Neurorehabil Neural Repair 22: 217-227.

192. Roche RA (2004) EEG alpha power changes reflect response inhibition deficits after traumatic brain injury (TBI) in humans. Neurosci Lett 362: 1-5.

193. Damasio AR (1998) The somatic marker hypothesis and the possible functions of the prefrontal cortex. In A. C. Roberts, T. W. Robbins \& L. Weiskrantz (Eds.), The prefrontal cortex: Executive and cognitive function (pp. 103-116). Oxford: Oxford University Press.

194. Rule RR (2002) Orbitofrontal cortex and dynamic filtering of emotional stimuli. Cogn Affect Behav Neurosci 2: 264-270.

195. Rolls ET (2000) The orbitofrontal cortex and reward. Cereb Cortex 10: 284-294.

196. Larson MJ (2009) Conflict adaptation and cognitive control adjustments following traumatic brain injury. J Int Neuropsychol Soc 15: 927-937.

197. Dockree PM, Robertson IH (2011) Electrophysiological markers of cognitive deficits in traumatic brain injury: a review. Int J Psychophysiol 82: 53-60.

198. Beres AM (2017) Time is of the Essence: A Review of Electroencephalography (EEG) and Event-Related Brain Potentials (ERPs) in Language Research. Applied psychophysiology and biofeedback 42: 247-255.

199. Fratantoni JM (2017) Electrophysiological Correlates of Word Retrieval in Traumatic Brain Injury. Journal of neurotrauma 34: 1017-1021.

200. Chiang HS (2014) Age-related changes in feature-based object memory retrieval as measured by event-related potentials. Biol Psychol 100: 106-114.

201. Chiang HS (2015) Altered neural activity during semantic object memory retrieval in amnestic mild cognitive impairment as measured by eventrelated potentials. $J$ Alzheimers Dis 46: 703-717.

202. Brier MR (2008) Event-related potentials in semantic memory retrieval. J Int Neuropsychol Soc 14: 815-822.

203. Key-DeLyria SE (2016) Sentence Processing in Traumatic Brain Injury: Evidence from the P600. J Speech Lang Hear Res 59: 759-771.

204. Tebano MT (1988) EEG spectral analysis after minor head injury in man Electroencephalogr Clin Neurophysiol 70: 185-189. 
Miranda P (2020) Event-related-potential (ERP) markers of traumatic brain injury (TBI) severity and cognitive function - Understanding how the brain works and thinks post TBI

205. Korn A (2005) Focal cortical dysfunction and blood-brain barrier disruption in patients with postconcussion syndrome. J Clin Neurophysiol 22: 1-9.

206. Tomkins O (2011) Blood-brain barrier breakdown following traumatic brain injury: a possible role in posttraumatic epilepsy. Cardiovasc. Psychiatry Neurol: 765923.

207. Gosselin N, Lassonde M, Petit D, Leclerc S, Mongrain V, Collie A, et al. (2009) Sleep following sport-related concussions. Sleep Med 10: 35-46.

208. Chen XP (2006a) Electroencephalogram and evoked potential parameters examined in Chinese mild head injury patients for forensic medicine. Neurosci Bull 22: 165-170.

209. Thornton K (2003) The electrophysiological effects of a bain injury on auditory memory functioning: qEEG correlates of impaired memory. Arch Clin Neuropsychol 18: $363-378$.

210. Watson SJ (1995) Biology of Schizophrenia and Affective Disease. Washington, DC: Amer. Psychiatric Press.

211. Hoffman DA (1995) Diagnosis and treatment of head injury. J Neurother 1: 14-21.

212. Kumar R (2009a) Comparative evaluation of corpus callosum DTI metrics in acute mild and moderate traumatic brain injury: its correlation with neuropsychometric tests. Brain Inj 23: 675-685.

213. Kumar S (2009b) Reduction of functional brain connectivity in mild traumatic brain injury during working memory. J Neurotrauma 26 : 665-676.

214. Slewa-Younan S (2002) Is 'gamma' $(40 \mathrm{~Hz})$ synchronous activity disturbed in patients with traumatic brain injury? Clin. Neurophysiol 113: 1640-1646.

215. Thatcher RW (1999) QEEG and traumatic brain injury: rebuttal of the American Academy of Neurology 1997 report by the EEG and Clinical Neuroscience Society. Clin Electroencephalogr 30: 94-98.

216. Thatcher RW (2000) EEG operant conditioning (biofeedback) and traumatic brain injury. Clin Electroencephalogr 31: 38-44.

217. Thatcher RW (2001) Estimation of the EEG power spectrum using MRI T2 relaxation time in traumatic brain injury. Clin Neurophysiol 112: 1729-1745.

218. Thatcher RW (2006) "Electroencephalography and mild traumatic brain injury," in Foundations of Sports Related Brain Injuries, eds S. M. Slobounov and W. J. Sebastianelli (New York, NY: Springer-Verlag): 241-266.

219. Cao C (2010) Alteration of cortical functional connectivity as a result of traumatic brain injury revealed by graph theory, ICA and sLORETA analyses of EEG signals. IEEE Trans. Neural Syst Rehabil Eng 18: 11-19.
220. Castellanos NP (2010) Reorganization of functional connectivity as a correlate of cognitive recovery in acquired brain injury. Brain 133: 2365-2381.

221. Castellanos NP (2011a) Alteration and reorganization of functional networks: a new perspective in brain injury study. Front Hum Neurosci 5: 90.

222. Castellanos NP (2011b) Principles of recovery from traumatic brain injury: reorganization of functional networks. Neuroimage 55: 1189-1199.

223. Nakamura T (2009) Resting network plasticity following brain injury. PLOS ONE 4: e8220.

224. Ham TE (2012) How can investigation of network function inform rehabilitation after traumatic brain injury? Curr Opin Neurol 25: 662-669.

225. Sponheim SR (2011) Evidence of disrupted functional connectivity in the brain after combat-related blast injury. Neuorimage 54: S21-S29.

226. Kasahara M (2010) Altered functional connectivity in the motor network after traumatic bain injury. Neurology 75: 168-176.

227. Tsirka V (2011) Mild traumatic brain injury: graph-model characterization of brain networks for episodic memory. Int J Psychophysiol 79: 89-96.

228. Thatcher RW (1991) Comprehensive predictions of outcome in closed head injury: the development of prognostic equations. Ann N Y Acad Sci 620: 82-104.

229. Zourdakis G (2011) Default brain connectivity network in mild traumatic brain injury - preliminary MEG results," in 2011 1st Middle East Conference on Biomedical Engineering (MECBME). Sharjah.

230. Irimia A (2013a) Forward and inverse electroencephalographic modeling in health and in acute traumatic brain injury. Clin Neurophysiol 124: 2129-2145.

231. Irimia A (2013b) Electroencephalographic inverse localization of brain activity in acute traumatic brain injury as a guide to surgery, monitoring and treatment. Clin Neurol Neurosurg 115: 2159-2165.

232. Goh SY (2014) Neuroinformatics challenges to the structural, connectomic, functional and electrophysiological multimodal imaging of human traumatic brain injury. Front Neuroinformatics 8: 19.

233. Bonita JD (2014) Time domain measures of inter-channel EEG correlations: a comparison of linear, nonparametric and nonlinear measures. Cogn Neurodyn 8 : $1-15$.

Copyright: (C2020 Miranda P. This is an open-access article distributed under the terms of the Creative Commons Attribution License, which permits unrestricted use, distribution, and reproduction in any medium, provided the original author and source are credited. 